\title{
Application of modern methods: modeling of sedimentary soil ESP content
}

PROFESSOR DR. SORUSH NIKNAMIAN

B oard Member of Weston A Price Foundation, Washington

D C, U S A

EMAIL: SO.NIKNAMIAN@GMAIL.COM

\section{A B S T R A C T}

Knowing the exchangeable sodium percentage (ESP) variations and its values in sodic or salinesodic soils is essential in order to estimate the amount of soil amendments and better land management. ESP calculated from cation exchange capacity (CEC), and since CEC measurement is difficult and time-consuming, ESP computation is costly and subject to error. Thus, presenting a method to estimate ESP indirectly, by an easily available index is much more efficient and economical. In this study, 296 soil samples collected and analyzed from Sistan plain, southeastern Iran. Soil ESP were predicted by using artificial neural networks (ANNs), comprising radial basis functions (RBFN) and multilayer perceptron (MLP) and adaptive neuro-fuzzy inference systems (ANFIS), and results compared with stepwise linear regression (SLR) method. Results indicated that the SLR models performed poorly in order to estimate ESP $\left(\mathrm{R}^{2} \leq 0.58\right.$ and root mean square error (RMSE $\geq 4.31$ ). Applying fewer inputs (electrical conductivity (EC and $\mathrm{pH}$ ), ANFIS showed better results $\left(\mathrm{R}^{2}=0.80, \mathrm{RMSE}=2.34\right)$, while increasing inputs (clay and organic carbon) decreased the accuracy $\left(\mathrm{R}^{2}=0.82, \mathrm{RMSE}=4.20\right)$. Using more inputs, $\mathrm{RBFN}$ resulted in better performance in comparison with other methods $\left(\mathrm{R}^{2}=0.83, \mathrm{RMSE}=2.85\right)$. Sensitivity analysis using the connection weight method demonstrated that $\mathrm{EC}, \mathrm{pH}$, clay percentage and bulk density are the most important variables in order to explain ESP variability in the region, respectively. Generally, considering the evaluation criteria and the number of used variables of models, ANFIS (with EC and $\mathrm{pH}$ as inputs) is the most appropriate method for estimating ESP in Sistan plain. 
1 Keywords: Saline-sodic soils, Exchangeable sodium percentage, PTFs, Computational 2 Intelligence, Sistan plain 


\section{1. Introduction}

2 Soil salinity and sodicity are main factors limiting crop growth in irrigated lands. Salinization is

3 the accumulation of solution salts in soil profiles, which limit yield production. When salt

4 accumulation exceeds crop threshold, its importance and effects would reveal. Too amount of salt

5 accumulation in soils is the result of low irrigation and high evaporation rate (Wang et al., 2008).

6 Currently, near 230 Mha of fields are irrigated worldwide, that 45 Mha of them (20\%) affected by

7 salinity (FAO, 2008). Sodicity is one of the most important attributes in saline soils, and influences

8 their physical and chemical properties (Farahmand et al., 2011). Sodicity is considerable when

9 exchangeable sodium percentage (ESP) exceeds $15 \%$ in soil. Soil structure degradation, decreasing

10 hydraulic conductivity, soil aeration and permeability, and increasing $\mathrm{pH}$ up to 8.5 , are main

11 reasons of lowering yield in sodic soils (Richards, 1954). Drainage, irrigation and changing crop

12 pattern are some measures to control soil salinity (Cetin and Kirda, 2003).

13 Approximately $10 \%$ of soils suffer from saline-sodic problem. Therefore, identifying and

14 managing regions with high salinity limitations are of the most important priorities in agriculture

15 (Barzegar, 2001). Exchangeable sodium to other exchangeable cations ratio is one of the most

16 imperative parameters for evaluating soil salinity and sodicity (Rohoades, 1968). In this regard,

17 ESP usually is the best index.

$18 \quad \mathrm{ESP}=\frac{\mathrm{Na}}{\mathrm{CEC}} \times 100$

19 Where:

$20 \mathrm{ESP}=$ Exchangeable sodium percentage, $\%$

$21 \mathrm{Na}^{+}=$Measured exchangeable $\mathrm{Na}, \mathrm{C}$ mol kg${ }^{-1}$

$22 \mathrm{CEC}=$ Cation exchange capacity, $\mathrm{C}$ mol kg-1 
1 Knowing the ESP variations and its values in sodic or saline-sodic soils, especially in agricultural

2 farms, is essential in order to estimate the amount of soil amendments and better land management.

3 ESP computation is time-consuming, costly and subject to error. Errors of ESP measurement relate

4 to CEC and exchangeable Na. Various error sources reported in measuring CEC by Bower method

5 (Bower et al., 1952), including remaining excess indicator cations during washing step, and the

6 existence of zeolite mineral in soil which resulted in overestimation of CEC and consequently ESP

7 would calculate less than its actual value. Moreover, not saturating exchanging parts with indicator

8 cation, in a full manner, soil wasting and hydrolysis of exchangeable indicator cation while

9 washing, not full replacing of sodium by ammonium and solution of gypsum, caused

10 underestimating CEC and overestiming ESP (Rhoades 1982). On the other hand, CEC

11 measurement is time-consuming and costly. When $\mathrm{EC}_{\mathrm{e}} \geq 10 \mathrm{dS} \mathrm{m}^{-1}$ (ECe $\mathrm{EC}$ for saturation extract),

12 exchangeable sodium measurement in soils would prone to errors related to anion expulsion effect.

13 Due to this errors, exchangeable sodium underestimates (Jurinak et al., 1984). Thus, presenting a

14 method to estimate ESP indirectly, by an easily available index is much more efficient and

15 economical way to overcome mentioned problems.

16 Knowledge of relations and correlations among different soil properties and expressing them by

17 statistical models are one of important issues in soil study. These models called pedo-transfer

18 functions (PTFs) and comprising regression and artificial neural network models (Minasny et al.,

19 2004). PTFs calculate soil attributes which are costly and time-consuming in measurement as

20 function of other properties that easily obtained. Primarily, PTFs used linear regression but

21 gradually it was replaced by nonlinear regression. Statistical regression assumes observations and

22 variables are exact; however, in natural systems such as soils they are not. Thus, it is imperative

23 to use methods for fitting functions that are capable of explaining vague structure of systems and 
1 producing actual patterns (Mohamadi and Taheri, 2005). Artificial neural networks (ANNs) are a

2 powerful tool for complicated computations and its easy applicability have been led to predictions

3 in various fields (Fortin et al., 2011; Jingwen et al., 2013 and Kurtulmus et al., 2013). In this regard,

4 nowadays ANNs that are inspired in a way that biological nervous systems works, applied widely.

5 An advantage of modeling methods which are based on calculation intelligence compared to

6 regression PTFs is that they do not need to previous information about relations between inputs

7 and outputs, and also their sensitivity to error in input data are less (Agyare and Park, 2007). In

8 other words, using minimum measured parameters, these models are able to predict target variables

9 variation, precisely. Sadrmomtazi et al. (2013) demonstrated that intelligent models predicted

10 more accurately than conventional regression models.

11 There have been developed many PTFs in order to estimate different soil properties till now. For

12 instance, Robbins and Meyer (1990) presented a model to predict ESP from pH and EC in sodic

13 soils of Australia. See Eq. (2).

$14 \quad \mathrm{ESP}=[(\mathrm{pH}-\mathrm{A}) \times(1+\mathrm{C} \times \mathrm{EC}) / \mathrm{B}]^{2}$

15 which A, B and C are soil specific coefficients. Furthermore, they proposed a second-order form 16 equation that its coefficients should modify for different soils. These researchers calculated A, B

17 and $\mathrm{C}$ ranges for different soil textures as follows: 4.62-6.95, 0.46-1.20 and 0.004-0.35, 18 respectively. Values of $R^{2}$ varies in range of 0.22 to 0.91 .

19 Sistan is one of the interior and flat plains of Iran plateau located in southeastern Iran, with 20 elevation ranging from 475 to 500 meters above sea level and covered by alluvial delta of the

21 Hirmand River and its surrounding floods. Considering dry climate, high groundwater levels, poor

22 annual rainfall, high evapotranspiration rate, and unsuitable water quality which utilized to irrigate

23 agricultural farms, salinity is a serious problem in this region and is expanding. Unfortunately, due 
1 to vastness of Sistan plain and difficult conditions for field investigations, soil studies and findings

2 in this area are very little. Planning for preventing and solving the problem of salinity in order to

3 improve soil quality and sustainable agricultural development is necessary and inevitable in this

4 area. The purpose of current study is investigating and suggesting relationships and models to

5 predict the amount of soil ESP from easily obtained properties of soil. Considering statistical

6 regression methods that have been used in previous studies, computational-intelligence-based

7 methods performance assessed. It was tried to present an accurate model with minimum input

8 variables and acceptable precision that does not need to costly and time-consuming laboratory

9 measurements for estimating ESP.

\section{2. Material and Methods}

\section{2.1. Description of the study area}

12 The study area is the Sistan plain located in the southeast of Iran, one of the driest regions of Iran 13 and famous for its "120 day wind", a highly persistent dust storm in the summer which blows from 14 north to south with velocities of nearly 20 knots. The Sistan delta has a very hot and dry climate.

15 In summer, the temperature exceeds $50^{\circ} \mathrm{C}$. Rainfall is about $55 \mathrm{~mm} \mathrm{year}^{-1}$ and occurs only in 16 autumn and winter. Surface evapotranspiration of the area is 4500 to $5000 \mathrm{~mm} \mathrm{year}^{-1}$. Strong 17 winds in the region are quite unique and are an important contributing factor for the high 18 evaporation (Fig. 1).

\section{2.2. Field and Laboratory Analyses}

20 Soil samples were collected from 296 points throughout study area. Soil samples were taken in

21 land with a high risk of salinization and/or sodification. Air-dried soil samples were passed through

22 a 2-mm sieve for selected chemical and physical measurements. 
1 The 1:5 and 1:1 soil to water extracts were prepared by adding $20 \mathrm{~mL}$ distilled water to $4 \mathrm{~g}$ and $20 \mathrm{~g}$

2 soil in a $100 \mathrm{~mL}$ bottles respectively. The bottles were sealed with a stopper, agitated for $15 \mathrm{~min}$

3 on a mechanical shaker $\left(100 \mathrm{r} \mathrm{min}^{-1}\right)$, allowed to stand for $1 \mathrm{~h}$, and then agitated again for $5 \mathrm{~min}$

4 before a sample was obtained by filtration (Chi and Wang, 2010). Organic carbon (OC), bulk

5 density (Bd), calcium carbonate equal (CCE), $\mathrm{pH}, \mathrm{EC}$, concentrations of $\mathrm{Na}^{+}, \mathrm{Ca}^{2+}$ and $\mathrm{Mg}^{2+}, \mathrm{CEC}$

6 and soil sample textures were determined (USDA-NRCS, 1996). The ESP was determined using

7 Eq. (1).

$8 \quad$ Figure1[near here]

9 Physical and chemical properties of soil samples were used for modeling ESP and evaluating the 10 accuracy of obtained model (Table 1).

11 Table1[near here]

12 2.3. Stepwise linear regression (SLR) model

13 An example of a SLR model is shown in the Eq. (3).

$14 Y=K_{1} X_{1}+\cdots+K_{n} X_{n}+d$

15 Where:

16 Y: dependent variable, for example, ESP of soil samples

$17 \mathrm{X}_{1}$ to $\mathrm{X}_{\mathrm{n}}$ : independent variables, for example the $\mathrm{EC}$ of soil samples,

$18 \mathrm{~K}_{1}$ to $\mathrm{K}_{\mathrm{n}}$ : regression coefficient,

19 d: intercept.

20 In order to estimate and modeling the ESP by EC and sodium adsorption ratio (SAR) of soil, a

21 SLR model was used. Before modeling, $85 \%$ of data assigned to simulation and $15 \%$ to test the

22 model. All SLR equations were fitted to the data using the Datafit software and the best regression

23 equations were selected. 
2 ANNs is useful computational way for predicting and modeling abstruse relationships among

3 parameters, especially when there is no explicit relation among parameters (Smith 1993; Gallant

4 1993). The ANN comprised of three layers: the input layer that all the data are imported to the

5 network and calculation the weight for each input variables are done, the hidden layer or layers,

6 that data are computed, and the output layer, that the ANN results are obtained. Every single layer

7 includes one or more fundamental section(s) called a node or a neuron (Dreyfus et al., 2011). The

8 problem is the key factor that determines the number of neurons in the layers. The small number

9 of hidden neurons is a limiting factor to learn the process carefully, however, too high number can

10 be very time-consuming and the network may overfit the data (Karunanithi et al., 1994).

11 In this study, three-layer multilayer perceptron (MLP) networks were constructed for computation

12 of the PTFs. All the computations were performed using the Excel 2003 and MATLAB (Version

13 7.12, Mathworks, Inc., Natick, MA, USA).

\section{2.5. MLP description}

15 The MLP network includes an input layer, hidden layers and an output layer (Fig. 2). In this study,

16 the inputs were $\mathrm{pH}$ and EC. The scaled values have been passed into the input layer and after that

17 propagated from the input layer to the next layer which is called hidden layer, before reaching the

18 output layer (Hussain et al., 2002). Each node in both hidden or output layer acts as a summing

19 junction. Using the following equation, inputs combine and modify from the previous layer

20 (Razavi et al., 2003; Jorjani et al., 2008).

$21 \quad Y_{i}=\sum_{j=1}^{i} X_{i} W_{i j}+b_{j}$

22 Which: 
$1 \mathrm{Y}_{\mathrm{i}}$ is the net input to node $\mathrm{j}$ in hidden or output layer,

$2 \mathrm{~W}_{\mathrm{ij}}$ is the weight related to neuron $\mathrm{i}$ and neuron $\mathrm{j}$,

$3 \mathrm{X}_{\mathrm{i}}$ is the input of neuron $\mathrm{j}$,

$4 \quad b_{j}$ is the bias connected to node $\mathrm{j}$.

$5 \quad$ Figure2[near here]

6 To avoid reduction in network speed and accuracy and to make data values equal, it is necessary

7 to normalize input data (Torrecilla et al., 2007). Normalization was done so that the mean of the

8 data series became 0.5 (Kumar et al., 2002). The following equation is used for normalizing data:

$9 \quad x_{n}=0.5\left[\frac{x-\bar{x}}{x_{\max }-x_{\min }}\right]+0.5$

10 where:

$11 \mathrm{x}_{\mathrm{n}}$ : normalized value,

$12 \mathrm{x}$ : actual value,

$13 \bar{x}$ : mean value,

$14 \quad \mathrm{x}_{\min }$ : minimum value,

$15 \mathrm{x}_{\max }$ : maximum value of parameter.

16 MLP network need sample series of input and output data for designing and training. In this study,

17 PTFs have been considered as network inputs and ESP as output data. Seventy (70), 15 and $15 \%$

18 of data were used to train, validate and test of MLP model, respectively.

19 MLP network applied for ANN modeling using MATLAB 7.12 software. Marquardt-Levenberg

20 learning rule and hyperbolic tangent function were used for training (Haykin 1994). Number of

21 neurons in hidden layer was computed by trial-and-error method and finally the best structure for

22 ESP was selected considering the greatest $\mathrm{R}^{2}$ value and the least RMSE.

\section{2.6. Radial basis function network (RBFN) model}


1 RBFNs is based on supervised learning. RBFN were independently proposed by many researchers

2 and are a popular alternative to the MLP and RBFN are also good at modeling nonlinear data and

3 can be trained in one stage rather than using an iterative process as in MLP and also learn the given

4 application quickly (Venkatesan and Anitha, 2006).

5 The structure of RBFN is similar to that of MLP. It consists of layer of neurons. The main

6 distinction is that RBFN has a hidden layer which contains nodes called RBFN units. Each RBFN

7 has two key parameters that describe the location of the function's center and its deviation or width.

8 The hidden unit measures the distance between an input data vector and the center of its RBF. The

9 RBFN has its peak when the distance between its center and that of the input data vector is zero

10 and declines gradually as this distance increases. There is only a single hidden layer in a RBF

11 network with two sets of weights, one connecting the hidden layer to the input layer and the other

12 connecting the hidden layer to the output layer. Those weights connecting to the input layer contain

13 the parameters of the basis functions. The weights connecting the hidden layer to the output layer

14 are used to form linear combinations of the activations of the basis functions (hidden units) to

15 generate the network outputs. Since the hidden units are nonlinear, the outputs of the hidden layer

16 may be combined linearly and so processing is rapid (Foody, 2004).

\section{2.7. Adaptive neuro-fuzzy inference system (ANFIS)}

18 The advantage of the fuzzy inference system is that it can deal with linguistic expressions and the

19 advantage of a neural network is that it can be trained and also can self-learn and self-improve.

20 Jang (1993) took both advantages, combining the two techniques, and proposed the ANFIS. The

21 idea behind neural network and fuzzy inference combination is to design a system that uses a fuzzy

22 logic to represent knowledge in an interpretable manner and has the learning ability derived from

23 a neural network that can adjust the membership functions parameters and linguistic rules directly 
1 from data in order to enhance the system performance (Wang et al., 2006). The ANFIS architecture

2 contains a five-layer feed forward neural network (Fig. 3). ANFIS is a hybrid intelligent system

3 which implements a Sugeno fuzzy inference system for a systematic approach to generate fuzzy

4 rules from a given input-output dataset (Negnevitsky, 2005).

5 A hybrid ANFIS algorithm based on the Sugeno system improved by Jang (1993) was used for

6 acquiring optimal output data in the study. The algorithm consists of the least-squares method and

7 the back-propagation algorithm. The first method was used for optimizing the consequent

8 parameters, while the second method in relation to fuzzy sets was employed to arrange the premise

9 parameters (Ubeyli and Guler, 2005).

10 Figure3[near here]

11 In this study in order to predict ESP using MLP and ANFIS, $\mathrm{EC}_{1: 5}$ and $\mathrm{pH}$ considered as inputs.

12 MLP had three layers (an input layer, one hidden layer and an output layer) and six neurons in the

13 hidden layer. Furthermore, ANFIS had five layers (input layer, input membership function layer,

14 rules layer, consequent layer and output layer) with three gaussian membership functions

15 (GaussMF) for input function.

16 2.8. Analysis

17 The $\mathrm{R}^{2}$, RMSE and model efficiency factor (MEF) used to compare models predicted soil ESP and

18 measured values and assess the performance of models.

$19 \mathrm{R}^{2}=1-\sum_{\mathrm{i}=1}^{\mathrm{n}}\left(\mathrm{y}_{\mathrm{i}}-\mathrm{y}_{\mathrm{di}}\right)^{2} / \sum_{\mathrm{i}=1}^{\mathrm{n}}\left(\mathrm{y}_{\mathrm{di}}-\mathrm{y}_{\mathrm{m}}\right)^{2}$

$20 \quad$ RMSE $=\sqrt{\frac{1}{n} \sum_{i=1}^{n}\left(y_{d i}-y_{i}\right)^{2}}$

$21 \quad \mathrm{MEF}=1-\frac{\sum_{1}^{\mathrm{n}}\left[\mathrm{y}_{\mathrm{di}}-\mathrm{y}_{\mathrm{i}}\right]^{2}}{\sum_{1}^{\mathrm{n}}\left[\mathrm{y}_{\mathrm{di}}-\mathrm{y}_{\mathrm{m}}\right]^{2}}$ 
1 where:

$2 \mathrm{n}$ : number of points,

$3 y_{i}$ : output value got from the neural network model,

$4 y_{d i}:$ experimental value,

$5 y_{m}$ : average of the experimental values.

\section{2.9. Sensitivity analysis for quantifying variable importance}

7 Prediction accuracy is a major benefit of ANN models, but the ANN models of any physical

8 processes are purely black box models, which do not explain the process being simulated and

9 whose utility is limited, without information regarding the relative importance of the parameters

10 in the system. The development of a method to couple input factors to meaningful outputs in ANN

11 models is of critical importance (Kemp et al., 2007). The data employed for developing ANN

12 models do contain important information regarding the physical process being simulated (Jain et

13 al., 2008).

14 A connection weight approach was used to evaluate the importance of inputs (soil moisture and

15 salinity) relative to output (crop yield) in ANNs. The connection weight method is to sum the

16 products of the input-hidden and the hidden-output connection weights between each input neuron

17 and output neuron for all input variables (Olden et al., 2004). The relative contributions of the

18 inputs to the output are dependent on the magnitude and direction of the connection weights. When

19 the signs of the input-hidden and hidden-output connection weights are the same (i.e., either both

20 are positive or negative), the input has a positive impact on the output. Contrarily, if the signs of

21 these connection weights are opposite, the specific input has a negative effect on the output. The

22 overall contribution of the input to the output depends on its sum of the positive and negative effect

23 across all different hidden nodes. The larger the sum of the connection weights, the greater the 
1 importance of the variable. The relative importance of input variable $i$ is determined through the

2 following formula:

$3 \quad \mathrm{RI}_{\mathrm{i}}=\sum_{\mathrm{j}=1}^{\mathrm{m}} \mathrm{W}_{\mathrm{ij}} \mathrm{W}_{\mathrm{jk}} / \sum_{\mathrm{i}=1}^{\mathrm{n}} \sum_{\mathrm{j}=1}^{\mathrm{m}} \mathrm{W}_{\mathrm{ij}} \mathrm{W}_{\mathrm{jk}} \times 100$

4 where:

$5 \quad \mathrm{RI}_{\mathrm{i}}$ : relative importance of the variable $\mathrm{i}(\mathrm{i}=1,2,3, \ldots, \mathrm{n})$ in the input layer on the output variable $6(\%)$.

$7 \mathrm{j}$ : index number of the hidden node $(\mathrm{j}=1,2,3, \ldots, \mathrm{m}), \mathrm{W}_{\mathrm{ij}}$ : connection weight between input

8 variable $\mathrm{i}$ and hidden node $\mathrm{j}, \mathrm{W}_{\mathrm{jk}}$ : connection weight between hidden node $\mathrm{j}$ and the output node

9 k. The whole computation was repeated for each output neuron.

\section{3. Results and Discussion}

\section{3.1. Descriptive statistics}

12 Descriptive statistics related to ESP and other soil properties have calculated (Table 1). Soil ESP

13 for study area are high (with an average of 16.3) which demonstrates the necessity for investigating 14 ESP variation as sodicity index of soils in Sistan plain. Correlation analysis (Perason coefficient) 15 applied amongst measured attributes and ESP using SAS software (Cary, NC., USA), and EC $\mathrm{E}_{1: 1}$ 16 and $\mathrm{EC}_{1: 5}$, clay percentage and soil $\mathrm{pH}$ were the most correlated variables (Table 2).

17 3.2. Modifying Robbins and Meyer Equation Coefficients

18 Table2[near here]

19 In this study, ESP modeled by the second-order form equation of Robbins and Meyer (1990) and

20 A, B and C coefficients computed for dry alluvial soils of Sistan plain (Table 3).

21 Table3[near here] 
1 According to statistic parameters of modified equation of Robbins and Meyer (1990), it could be

2 concluded that nonlinear form of this equation is not able to explain ESP variation in study area,

3 accurately. This conclusion supported in Fig. 4.

4 Figure4[near here]

5 3.3. Suggested Regression Models to Predict ESP in Dry Alluvial Soils

6 As Robbins and Meyer (1990) used EC and pH to predict ESP in sodic soils of Australia and

7 reported that their model is economic, time-efficient and potentially able to calculate ESP from

8 easily obtained data, in current study firstly, all parameters which measured in laboratory

9 (comprising $\mathrm{EC}_{1: 5}, \mathrm{pH}$, clay, $\mathrm{OC}, \mathrm{CCE}, \mathrm{Bd}$, silt and sand) considered as inputs for model. Final

10 model used only $\mathrm{EC}_{1: 5}$ and $\mathrm{pH}$ as required data (Table 4).

11 Although the second regression model (Table 4) used more inputs than the first one, it is not able

12 to explain more than $56 \%$ of ESP variations. In other words, $44 \%$ of ESP variability refers to

13 factors that were not considered in regression model. Parts of this discrepancy can ascribe to

14 nonlinear relations among ESP, EC and other soil properties which SLR models have not sufficient

15 capability to recognize them.

16 Table4[near here]

17 Comparing measured and predicted values of ESP using regression models revealed that variation

18 ranges of outputs in model 1 is narrower than model 2, while results of second model showed some

19 overestimation (Figs. 5 and 6).

20 Figure5[near here]

21 Figure6[near here] 
1 The purpose of this research was to present a model requiring as low as possible data which are

2 easily obtainable. Since using soil parameters (other than EC and $\mathrm{pH}$ ) did not improve model and

3 also these parameters obtained easily, $\mathrm{EC}$ and $\mathrm{pH}$ are appropriate inputs for ESP estimate.

4 Regression models obtained, are different from Robbins and Meyer (1990). Therefore, relations

5 between ESP and soil attributes are not consistent and influenced by several factors such as EC

6 (Jurinak et al., 1984), ionic solution concentration (Shainberg et al., 1980), soil salinity (Frenkel

7 and Alperovitch, 1983), and clay minerals and its components (Endo et al., 2002).

8 3.4. The Artificial Neural Networks and ANFIS modeling

9 In order to predict ESP by artificial intelligence methods (MLP, RBFN and ANFIS) using easily-

10 obtained soil properties and comparing results with SLR, two models considered. First model

11 comprised EC and $\mathrm{pH}$ as inputs, while in the second one, all measured parameters considered (EC,

$12 \mathrm{pH}$, clay, $\mathrm{OC}, \mathrm{CCE}, \mathrm{Bd}$, silt and sand).

13 During training phase, the best numbers of neurons in hidden layer and the best function in neurons

14 of hidden layer for improving precision of training phase selected by trial and error. Modeling

15 results illustrate in Table 5.

16 Table5[near here]

17 Results showed that aiming at estimating ESP by model 1 (inputs: EC and $\mathrm{pH}$ ), ANFIS is the most 18 efficient model $\left(\mathrm{R}^{2}=0.80\right.$, $\mathrm{RMSE}=2.34$ and $\left.\mathrm{MEF}=0.81\right)$. MLP and $\mathrm{RBFN}$ are suitable, too,

19 however, as shown in Fig. 7, ANFIS outputs are more comparable with input data and ESP 20 predicted better. Generally, computational intelligence methods (MLP, RBFN and ANFIS) were

21 more capable to predict ESP from EC and pH (model 1). Erzin and Gunes (2011) estimated swell

22 percent and swell pressure of soil by using ANN and SLR and reported that ANN performed

23 significantly better than SLR. They presented ANN as an inexpensive and rapid alternative for 
1 laboratory methods to predict swell percent and swell pressure of soil. Estimating soil parameters

2 from more readily available soil data in Ziyaran region, Keshavarzi et al. (2010) concluded that

3 the ANN model with five neurons in hidden layer gives better estimates of field capacity and

4 permanent wilting point than the multivariate regression model. Singh and Deo (2007) in their

5 study to forecast daily river flows along river Narmada in India, using ANFIS, generalized

6 regression neural network (GRNN) and RBFN, found out ANFIS and RBFN are more precise than

7 GRNN and MLP. Amutha and Prochelvan (2011) after studying the seasonal ground water levels

8 in Malattar sub-watershed, located in Vellore district, Tamilnadu, India, assessed performances of

9 ANFIS and RBFN. Both models had 3 inputs. The results showed that the ANFIS is better when

10 compared to RBFN.

11 Figure7[nere here]

12 Increasing inputs changed results in which RBFN has better outcomes in comparison with ANFIS

13 and MLP $\left(\mathrm{R}^{2}=0.83\right.$, RMSE $=2.85$ and $\left.\mathrm{MEF}=0.80\right)$. Outputs of $\mathrm{RBFN}$ are more consistent with input

14 data and ESP predicted better (Fig. 8). Yilmaz and Kaynar (2011) in order to determine the swell

15 potential of clay soils, applied MLP, RBFN, ANFIS and (SLR) models. They reported that MLP

16 and ANFIS have quite the same results and RBFN is the best model. Increasing inputs in ANFIS

17 resulted in increasing error, however, for MLP and RBFN this was vice versa, and although $\mathrm{R}^{2}$

18 improved to some extent, RMSE improved significantly (Table 5).

19 Figure8[nere here]

20 General comparing among artificial intelligence methods aiming at ESP modeling, implied that

21 ANFIS outperforms RBFN and MLP. Despite the fact that statistical parameters showed good

22 performance of RBFN (model 2), ANFIS (model 1) is more desirable because of lesser inputs

23 (compared with 8 inputs in RBFN 2 which required more time and cost to determine), easy 
1 measurement and obtaining. Karami and Afiuni-Zadeh (2012) for modeling of sizing of rock

2 fragmentation due to bench blasting by estimation of $80 \%$ passing size (K80) of Golgohar iron ore

3 mine of Sirjan, Iran, found out that ANFIS is superior to RBFN. They expressed that using only

4 two input parameters in ANFIS is the reason of its superiority over RBFN with seven inputs.

5 Investigating histogram curves for the best models of ESP prediction shows better estimates of

6 ANFIS (model 1) using EC and $\mathrm{pH}$ as inputs and RBFN (model 2) using all parameters (Fig. 9).

7 Frequencies of error percent in RBFN (model 2) is closer to zero and has the least variation range

8 and also SD (5.76), which implies its ability for modeling ESP employing more inputs, compared

9 to other models. Furthermore, regression model has the widest curve and the most error variations

10 (Fig. 9), however, SD for ANFIS (model 1) (2.62) is lesser than others that resulted to lesser error

11 (RMSE=2.34) and more accuracy to estimate ESP (Fig. 9-d).

12 Figure9[near here]

13 Table6[near here]

14 In order to find the importance of used variables, the best model including all inputs (RBFN 2)

15 considered. Then, connection weights between input variables and hidden nodes $\left(\mathrm{W}_{\mathrm{ij}}\right)$ and

16 connection weights between hidden nodes and the output nodes $\left(\mathrm{W}_{\mathrm{jk}}\right)$ derived (Table 6$)$. Finally,

17 sensitivity of all inputs of RBFN 2 calculated using equation 9 (Fig. 10). This figure illustrates that

$18 \mathrm{EC}_{1: 5}, \mathrm{pH}$, clay percent and $\mathrm{Bd}$, sort by relevance, are the most important parameters regarding

19 ESP estimation in alluvial soils of Sistan plain.

20 Figure10[near here]

\section{4. Conclusions}

22 In this study, the feasibility of predicting ESP by soil easily-obtained properties assessed using

23 different methods. ESP estimated by regression models and results implied that they have not 
1 acceptable performance $\left(\mathrm{R}^{2} \leq 0.58, \mathrm{RMSE} \geq 4.31\right.$ and $\left.\mathrm{MEF} \geq 39\right)$. However, using more inputs

2 improved estimation in regression model 2 and partial $\mathrm{R}^{2}$ values showed the effect of $\mathrm{EC}$, clay, $\mathrm{pH}$

3 and OC, sort by relevance, in approximating ESP. Then, artificial intelligence models utilized with

4 the same inputs, which demonstrated better results than regression.

5 When used less inputs (model 1), ANFIS are the most efficient model $\left(\mathrm{R}^{2}=0.80\right.$, $\mathrm{RMSE}=2.34$,

$6 \mathrm{MEF}=0.81$ and $\mathrm{SD}=2.62$ ), while increasing inputs (model 2) lowered the accuracy $\left(\mathrm{R}^{2}=0.82\right.$,

$7 \quad \mathrm{RMSE}=4.20$ and $\mathrm{MEF}=0.71)$.

8 Increase in number of input data beside control number of neurons in middle layer, made the RBFN

9 (model 2) the most powerful model $\left(\mathrm{R}^{2}=0.83\right.$, $\mathrm{RMSE}=2.85$ and $\left.\mathrm{MEF}=0.80\right)$. Results showed that

10 RBFN, ANFIS and MLP are able to predict ESP fro easily-obtained properties of soils, accurately.

11 Considering results of suggested models (1 and 2) for estimating ESP and according to number of

12 input data beside evaluation criteria, model 1 (inputs: $\mathrm{EC}$ and $\mathrm{pH}$ ) proposes. ANFIS reported the

13 best estimates by this model. Moreover, the other advantage is less inputs that require less time

14 and cost to obtain compared to required data in model 2. Sensitivity analysis results for applied

15 variables regarding ESP estimation revealed that $\mathrm{EC}, \mathrm{pH}$, clay percentages and bulk density are

16 the most important data.

17 In total, due to superiority of artificial intelligence models compare to SLR, it is possible to use

18 soil easily-obtained properties such as EC and $\mathrm{pH}$ to estimate ESP. It is imperative to conduct 19 similar researches in different soils. 
Agyare, W.A., Park, S. J., 2007. Artificial neural network estimation of saturated hydraulic conductivity. Vadose Zone Journal, 6, 423-431.

Amutha, R., Porchelvan, P., 2011. Seasonal Prediction of Groudwater levels using ANFIS and Radial Basis Neural Network. International Journal of Geology, Earth and Environmental Sciences, 1, 98-108.

Barzegar, A., 2001. Saline and Sodic Soils: Productivity and Efficiency. Urmia University Press. 8 (in Persian)

Bower, C.A., Reitemeier, R.F., Fireman, M., 1952. Exchangeable cation analysis of saline and alkali soils. Soil Science, 73, 251-261.

Cetin, M., Kirda, C., 2003. Spatial and temporal changes of soil salinity in a cotton field irrigated with low-quality water. Journal of Hydrology, 272, 238-249.

Chi, C.M., Wang, Z.C., 2010. Characterizing salt-affected soils of Songnen Plain using saturated paste and 1:5 soil-to-water extraction methods. Arid Land Research and Management, 24, 1-11.

Dreyfus, G., Martinez, J.M., Samuelides, M., Gordon, M.B., Badran, F., Thiria, S., 2011. Apprentissage statistique: Réseaux de neurones-Cartes topologiques-Machines à vecteurs supports: Eyrolles.

Endo, T., Yamamoto, S., Honna, T. Eneji, A.E., 2002. Sodium-calcium exchange selectivity as influenced by clay minerals and composition. Soil Science, 167, 117-125.

Erzin, Y., Güneş, N., 2011. The prediction of swell percent and swell pressure by using neural networks. Mathematical and Computational Applications, 16,425-436.

Farahmand, A., Oustan, S.H., Jafarzadeh, A.J., Asgarzad, A.N., 2011. The parameters of sodium and salinity in some salt affected soils of the Tabriz Plain. Journal of Soil and Water, 22, 1-15. (In persian)

Food and Agriculture Organization of the United Nations 2008. Land Resources, Management, Planning and Use. http://www.fao.org/ag/agl/agll/spush.

Foody, G.M., 2004. Supervised image classification by RBFN and MLP and neural networks with and without an exhaustively defined set of classes. International Journal of Remote Sensing, 25, 3091-3104.

Fortin, J.G., Anctil, F., Parent, L.E., Bolinder, M.A., 2011. Site-specific early season potato yield forecast by neural network in Eastern Canada. Precision Agriculture. 12, 905-923.

Frenkel, H., Alperovitch, N., 1983. Factors affecting the estimation of exchangeable sodium percentage in soils from Israel. Hassadeh, 63, 1291-1296.

34 Gallant, S.I., 1993. Neural network learning and expert systems: MIT press. Cambridge, MA.

35 Haykin, S. 1994. Neural Networks: A Comprehensive Foundation. Macmillan, New York.

Hussain, M., Shafiur Rahman, M., Ng, C., 2002. Prediction of pores formation (porosity) in foods during drying: generic models by the use of hybrid neural network. Journal of Food Engineering, 38 51, 239-48.

39 Jain, S.K., Nayak, P.C., Sudheer, K.P., 2008. Models for estimating evapotranspira- tion using 40 artificial neural network, and their physical interpretation. Hydrological Processes, 22, 2225-2234. 
Jang, J.S.R., 1993. ANFIS-Adaptive-network-based fuzzy inference system. IEEE Transactions

2 System Man Cybernetics, 23, 665-658.

3 Jingwen, Z., Zhenghong, X., Shouwen, Ch., 2013. Simulation and prediction of the thuringiensin 4 abiotic degradation processes in aqueous solution by a radius basis function neural network model. 5 Chemosphere, 91, 442-447.

Jorjani, E., Chehreh Chelgani, S., Mesroghli, S., 2008. Application of artificial neural networks to predict chemical desulfurization of Tabas coal. Fuel, 87, 2727-2734.

Jurinak, J.J., Amrhein, C., Wagenet, R.J., 1984. Sodic hazard: The effect of SAR and salinity in soils and overburden materials. Soil Science, 137, $152-158$.

Karami, A., Afiuni-zadeh, S., 2012. Sizing of rock fragmentation modeling due to bench blasting using adaptive neuro-fuzzy inference system and radial basis function. International Journal of Mining Science and Technology, 22, 459-463.

13 Karunanithi, N., Grenney, W.J., Whitley, D., Bovee, K., 1994. Neural networks for river flow prediction. Journal of Computing in Civil Engineering, 8, 201-20.

Kemp, S., Zaradic, P., Hansen, F., 2007. An approach for determining relative input parameter importance and significance in artificial neural networks. Ecological Modelling, 204, 326-334.

Keshavarzi, A., Sarmadian, F., Sadeghnejad, M., Pezeshki, P., 2010. Developing Pedotransfer Functions for Estimating some Soil Properties using Artificial Neural Network and Multivariate Regression Approaches. Pro Environment, 3, 322-330.

Kumar, M., Raghuwanshi, N.S., Singh, R., Wallender, W.W., Pruitt, W.O., 2002. Estimating evapotranspiration using artificial neural network. Journal of Irrigation and Drainage Engineering, 128, 224-233.

Kurtulmus, F., Lee, W.S., Vardad, A., 2013. Immature peach detection in colour images acquired in natural illumination conditions using statistical classifiers and neural network. Precision Agriculcture, 15, 57-79.

Minasny, B., Hopman, J., Harter, W.T., Eching, S.O., Toli, A., Denton, M.A., 2004. Neural networks prediction of soil hydraulic functions for alluvial soils using multistep outflow data. Soil science Society American Journal, 68. 417- 429.

Mohamadi, J., Tahri, S.M., 2005. Fitting the pedotransfer functions by using the fuzzy regression. Science and Technology of Agriculture and Natural Resources, 2, 51-60. (In Persian)

Negnevitsky, M., 2005. Artificial Intelligence: a guide to intelligent systems. Pearson Education Limited, Essex, England.

Olden, J.D., Joy, M.K., Death, R.G., 2004. An accurate comparison of methods for quan- tifying variable importance in artificial neural networks using simulated data. Ecol. Model. 178, 389-397.

Razavi, M.A., Mortazavi, A., Mousavi, M., 2003. Dynamic modelling of milk ultrafiltration by artificial neural network. Journal of Membrane Science. 220, 47-58.

Rhoades, J.D., 1968. Mineral weathering correction for estimating the sodium hazard of irrigation waters. Soil Science Society of America Proceedings, 32, 648-652.

Rhoades, J.D., 1982. Cation exchange capacity. In A. L. Page et al., (Ed.), Methods of Soil Analysis. Soil Science Society of American, Madison, WI.

Richards, L.A., 1954. Diagnosis and improvement of saline and alkali soils. In USDA Handbook 60. U. S. Department of Agriculture, Washington, DC. 
Robbins, C.W., Meyer, W.S., 1990. Calculating pH from EC and SAR values in salinity models and SAR from soil and bore water $\mathrm{pH}$ and EC data. Australian Journal of Soil Research, 28, 10011011.

4 Sadrmomtazi, A., Sobhani, J., Mirgozar, M.A., 2013. Modeling compressive strength of EPS lightweight concrete using regression, neural network and ANFIS. Journal of Construction and Building Materials, 42, 205-216.

Shainberg, I., Oster, J. D., Wood, J.D., 1980. Sodium calcium exchange in montmorillonite and illite suspensions. Soil Science Society of America Journal, 44, 960-964. Singh, P., Deo, M.C., 2007. Suitability of Different Neural Networks in Daily Flow Forecasting. Applied Soft Computing, 7, 968-978.

11 Smith, M., 1993. Neural networks for statistical modeling: Thomson Learning.

12 Soil Survey Staff 1996. Soil survey laboratory methods manual. Soil Survey Investigations Rep. 13 42. Version 3.0. U.S. Gov. Print. Washington, DC.

14 Torrecilla, J., Otero, L., Sanz, P., 2007. Optimization of an artificial neural network for thermal/pressure food processing: Evaluation of training algorithms. Computers and Electronics in Agriculture, 56: 101-10.

Ubeyli, E. D., Guler, I., 2005. Adaptive Neuro-Fuzzy Inference Systems for Analysis of Internal Carotid Arterial Doppler, Signals Computers in Biology and Medicine, 35, 687-702.

USDA-NRCS, 1996. Soil Survey Laboratory Methods Manual. Soil Survey Investigations Report, No. 42.Version 3.0. Nebraska.

Venkatesan, P., Anitha, S., 2006. Application of a radical basis function neural network for diagnosis of diabetes mellitus. Current Science, 91, 1195-1199.

Wang, Y.G., Xiao, D.N., Li, Y., Li, X.Y., 2008. Soil salinity evolution and its relationship with dynamics of groundwater in the oasis of inland river basins: case study from the Fubei region of Xinjiang province. China Environmental Monitoring and Assessment, 140, 291-302.

Wang, Z., Palade, V., Xu, Y., 2006. Neuro-fuzzy ensemble approach for microarray cancer gene expression data analysis. In Evolving Fuzzy Systems. 2006 International Symposium on, 241-246. Yilmaz, I., Kaynar, O., 2011. Multiple regression, ANN (RBF, MLP) and ANFIS models for prediction of swell potential of clayey soils. Expert Systems with Applications, 38, 5958-5966. 


\begin{tabular}{lccccccc}
\hline Variable & Unit & Mean & Minimum & Maximum & SD & Variance & $\mathrm{CV}$ \\
\hline Clay & $\%$ & 23.2 & 7.1 & 49.5 & 9.20 & 84.9 & 39.8 \\
Silt & $\%$ & 42.5 & 0.0 & 82.0 & 14.6 & 212 & 34.2 \\
Sand & $\%$ & 34.6 & 2.6 & 85.0 & 18.2 & 330 & 52.9 \\
Bd & $\mathrm{Gr} \mathrm{cm}^{-3}$ & 1.39 & 0.8 & 1.89 & 0.36 & 0.13 & 25.4 \\
$\mathrm{OC}$ & $\%$ & 0.52 & 0.04 & 1.26 & 0.25 & 0.06 & 47.7 \\
$\mathrm{EC}$ & $\mathrm{dS} \mathrm{m}^{-1}$ & 4.61 & 0.2 & 115.8 & 9.75 & 95.1 & 211.5 \\
$\mathrm{pH}$ & $\log \left[\mathrm{H}^{+}\right]$ & 8.84 & 7.7 & 10.3 & 0.53 & 0.28 & 5.98 \\
$\mathrm{Na}$ & $\mathrm{Cmol} \mathrm{kg}^{-1}$ & 3.08 & 1.03 & 9.32 & 1.33 & 1.77 & 43.3 \\
ESP & $\mathrm{Cmol} \mathrm{kg}^{-1}$ & 23.9 & 5.86 & 59.7 & 9.20 & 84.5 & 38.4 \\
CEC & $\mathrm{Cmol} \mathrm{kg}^{-1}$ & 13.3 & 5.92 & 34.0 & 4.47 & 19.9 & 33.55 \\
\hline
\end{tabular}

SD: standard deviation, CV: Coefficient of variation, Bd: bulk density, OC: organic carbon,

CEC: cation exchange capaci

\begin{tabular}{|c|c|c|c|c|c|c|c|c|c|}
\hline & Clay & CCE & Silt & Sand & $\mathrm{Bd}$ & $\mathrm{OC}$ & $\mathrm{EC}_{1: 1}$ & $\mathrm{EC}_{1: 5}$ & $\mathrm{pH}$ \\
\hline ESP & $0.32^{* *}$ & $0.14^{*}$ & $0.27^{* *}$ & $-0.37^{* *}$ & 0.05 & -0.05 & $0.68^{* *}$ & $0.70^{* * *}$ & $0.35^{* *}$ \\
\hline
\end{tabular}




\begin{tabular}{ccccccc}
\hline Equation form & A & B & C & RMSE & R $^{2}$ & MEF \\
\hline $\mathrm{ESP}=[(\mathrm{pH}-\mathrm{A}) \times(1+\mathrm{C} \times \mathrm{EC}) / \mathrm{B}]^{2}$ & 7.22 & 4.28 & 0.0199 & 4.53 & 0.50 & 0.33
\end{tabular}




\begin{tabular}{|c|c|c|c|c|c|c|}
\hline Models & Step & $\begin{array}{l}\text { Variable } \\
\text { Entered }\end{array}$ & $\begin{array}{c}\text { Partial } \\
\text { R-Square }\end{array}$ & $\begin{array}{c}\text { Model } \\
\text { R-Square }\end{array}$ & F Value & $\operatorname{Pr}>\mathrm{F}$ \\
\hline \multirow[t]{2}{*}{ Reg Model 1} & 1 & $\mathrm{EC}_{1: 5}$ & 0.49 & 0.49 & 286.74 & $<.0001$ \\
\hline & 2 & $\mathrm{pH}$ & 0.02 & 0.52 & 14.01 & 0.0002 \\
\hline \multirow{4}{*}{ Reg Model 2} & 1 & $\mathrm{EC}_{1: 5}$ & 0.49 & 0.49 & 286.73 & $<.0001$ \\
\hline & 2 & Clay & 0.04 & 0.53 & 20.19 & $<.0001$ \\
\hline & 3 & $\mathrm{pH}$ & 0.02 & 0.56 & 14.91 & 0.0001 \\
\hline & 4 & $\mathrm{OC}$ & 0.01 & 0.58 & 3.65 & 0.0572 \\
\hline \multicolumn{7}{|c|}{ Final Results } \\
\hline Models & \multicolumn{3}{|c|}{ Pedotransfer function } & \multicolumn{2}{|r|}{$\mathrm{R}^{2}$} & $\mathrm{MEF}$ \\
\hline Reg 1 & \multicolumn{3}{|c|}{$\mathrm{ESP}=0.748 \mathrm{EC}_{1: 5}+1.98 \mathrm{pH}-3.858$} & & 0.52 & 0.39 \\
\hline $\operatorname{Reg} 2$ & \multicolumn{3}{|c|}{$\begin{array}{l}\mathrm{ESP}=0.7 \mathrm{EC}_{1: 5}+0.155 \text { Clay }+1.764 \mathrm{pH}- \\
2.161 \mathrm{OC}-4.1994\end{array}$} & \multicolumn{2}{|c|}{4.34} & 0.50 \\
\hline
\end{tabular}

All variables Entered left in the model are significant at the 0.1000 level 


\begin{tabular}{|c|c|c|c|c|c|c|c|c|}
\hline \multirow[b]{2}{*}{ Model } & \multicolumn{5}{|c|}{ MLP } & \multirow[b]{2}{*}{ RMSE } & \multirow[b]{2}{*}{$\mathrm{R}^{2}$} & \multirow[b]{2}{*}{ MEF } \\
\hline & Input & $\begin{array}{c}\text { Layer } \\
\text { No. }\end{array}$ & $\begin{array}{l}\text { Hidden } \\
\text { layer } \\
\text { neurons }\end{array}$ & HLF $^{*}$ & $\mathrm{OLF}^{*}$ & & & \\
\hline 1 & \multirow{2}{*}{$\begin{array}{c}\mathrm{EC}_{1: 5}+\mathrm{pH} \\
8 \\
\text { parameters }^{* *}\end{array}$} & 3 & 4 & tribas & Purelin & 3.95 & 0.74 & \multirow{2}{*}{$\begin{array}{l}0.69 \\
0.75\end{array}$} \\
\hline \multirow[t]{2}{*}{2} & & 3 & 6 & tansig & Purelin & 3.65 & 0.76 & \\
\hline & \multicolumn{5}{|c|}{ RBFN } & & & \multirow[b]{2}{*}{$\mathrm{MEF}$} \\
\hline Model & Input & Spread & $\begin{array}{l}\text { Hidden } \\
\text { layer } \\
\text { neurons }\end{array}$ & $\mathrm{HLF}^{*}$ & $\mathrm{OLF}^{*}$ & RMSE & $\mathrm{R}^{2}$ & \\
\hline 1 & \multirow{2}{*}{$\begin{array}{c}\mathrm{EC}_{1: 5}+\mathrm{pH} \\
8 \\
\text { parameters }^{* *}\end{array}$} & 0.7 & 5 & gaussian & Liner & 3.55 & 0.77 & \multirow{2}{*}{$\begin{array}{l}0.74 \\
0.80\end{array}$} \\
\hline \multirow[t]{2}{*}{2} & & 1 & 10 & gaussian & Liner & 2.85 & 0.83 & \\
\hline & & & ANFIS & & & & & \multirow[b]{2}{*}{ MEF } \\
\hline Model & Input & $\begin{array}{c}\text { Layer } \\
\text { No. }\end{array}$ & Rules & $\mathrm{IMF}^{*}$ & $\mathrm{OMF}^{*}$ & RMSE & $\mathrm{R}^{2}$ & \\
\hline 1 & \multirow{2}{*}{$\begin{array}{c}\mathrm{EC}_{1: 5}+\mathrm{pH} \\
8 \\
\text { parameters }^{* *}\end{array}$} & 5 & 9 & gaussMF & liner & 2.34 & 0.80 & \multirow{2}{*}{$\begin{array}{l}0.81 \\
0.71\end{array}$} \\
\hline 2 & & 5 & 4 & gaussMF & liner & 4.20 & 0.82 & \\
\hline
\end{tabular}

*HLF: hidden layer function, OLF: output layer function, IMF: input membership function, OMF: output membership function, LIF: input layer function

** 8 parameters: $\mathrm{EC}_{1: 5}, \mathrm{pH}$, clay, silt, sand, organic carbon, carbonate calcium equivalent, density 


\begin{tabular}{|c|c|c|c|c|c|c|c|c|c|c|}
\hline \multicolumn{11}{|c|}{ Input weight } \\
\hline & Neuron1 & Neuron2 & Neuron3 & Neuron4 & Neuron5 & Neuron6 & Neuron7 & Neuron8 & Neuron9 & $\mathrm{Neu}$ \\
\hline $\mathrm{CCE}$ & 0.4814 & 0.591 & 0.6458 & 0.4745 & 0.454 & 0.4951 & 0.4198 & 0.2622 & 0.4951 & 0.2 \\
\hline $\mathrm{Bd}$ & 0.7087 & 0.7087 & 0.4655 & 0.4334 & 0.6674 & 0.6903 & 0.3555 & 0.6353 & 0.4472 & \\
\hline $\mathrm{OC}$ & 0.4324 & 0.440 & & 0.46 & & & & & & \\
\hline Clay & 0.7059 & 0.6163 & 0.3757 & 0.4182 & 0.4418 & 0.3686 & 0.4182 & 0.5 & 0.4076 & \\
\hline Silt & 0.5875 & 0.5631 & 0.4351 & 0.4656 & 0.5814 & 0.679 & 0.4107 & 0.3497 & 0.5326 & 0 \\
\hline Sand & 0.3065 & 0.3769 & 0.6281 & 0.576 & 0.4485 & 0.3891 & 0.6306 & 0.6427 & 0.5147 & \\
\hline $\mathrm{EC}_{1: 5}$ & 0.6792 & 0.5089 & 0.4616 & 25 & & & & & 0.4661 & 0.4 \\
\hline pH & 0.7391 & 0.6741 & & & 0.5009 & 0.4635 & 0.4969 & & 0.493 & 0.5 \\
\hline \multicolumn{11}{|c|}{ Layer weight } \\
\hline & Neuron1 & Neuron2 & Neuron3 & Neuron4 & Neuron5 & Neur & Neuron7 & $\mathrm{Neu}$ & on9 & $\mathrm{Neu}$ \\
\hline & 2.0593 & -0.6136 & 3.8075 & -18.0898 & -0.6824 & 0.5658 & 5.564 & 4.4402 & 8.4618 & -4 \\
\hline
\end{tabular}




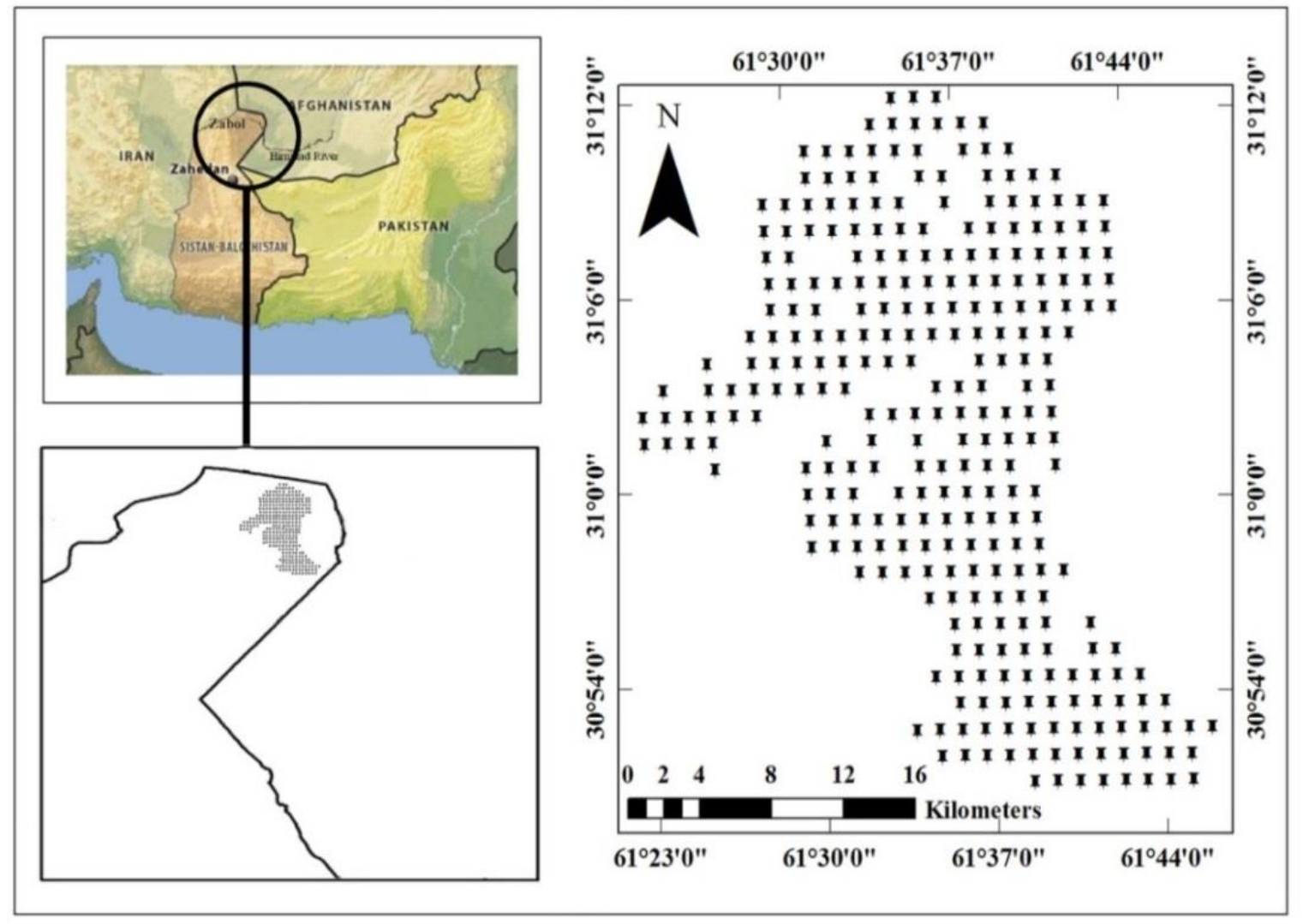




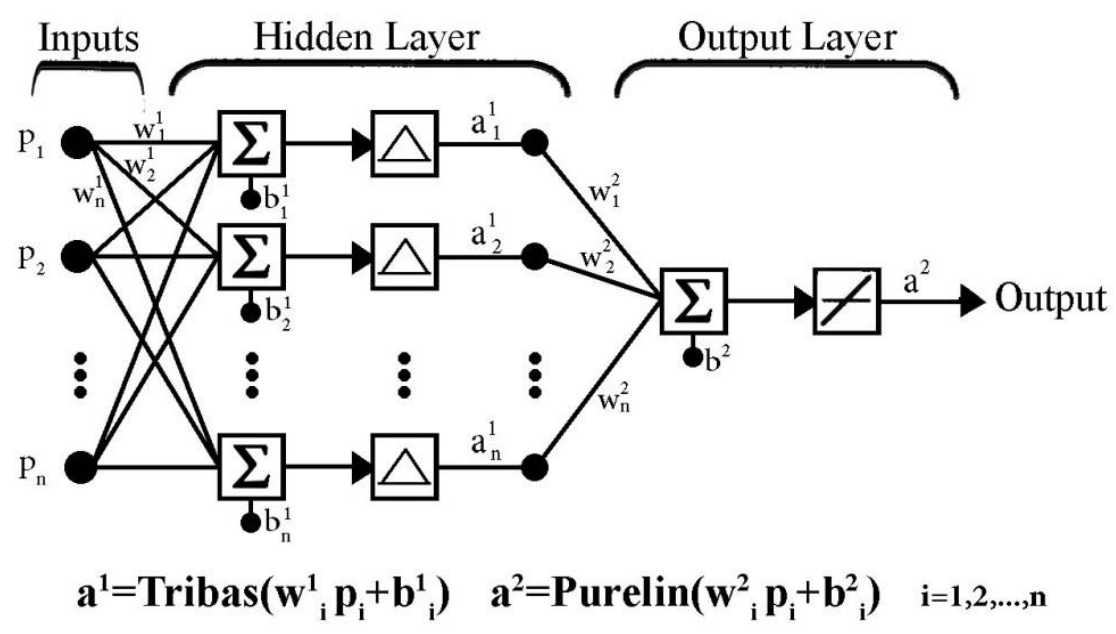



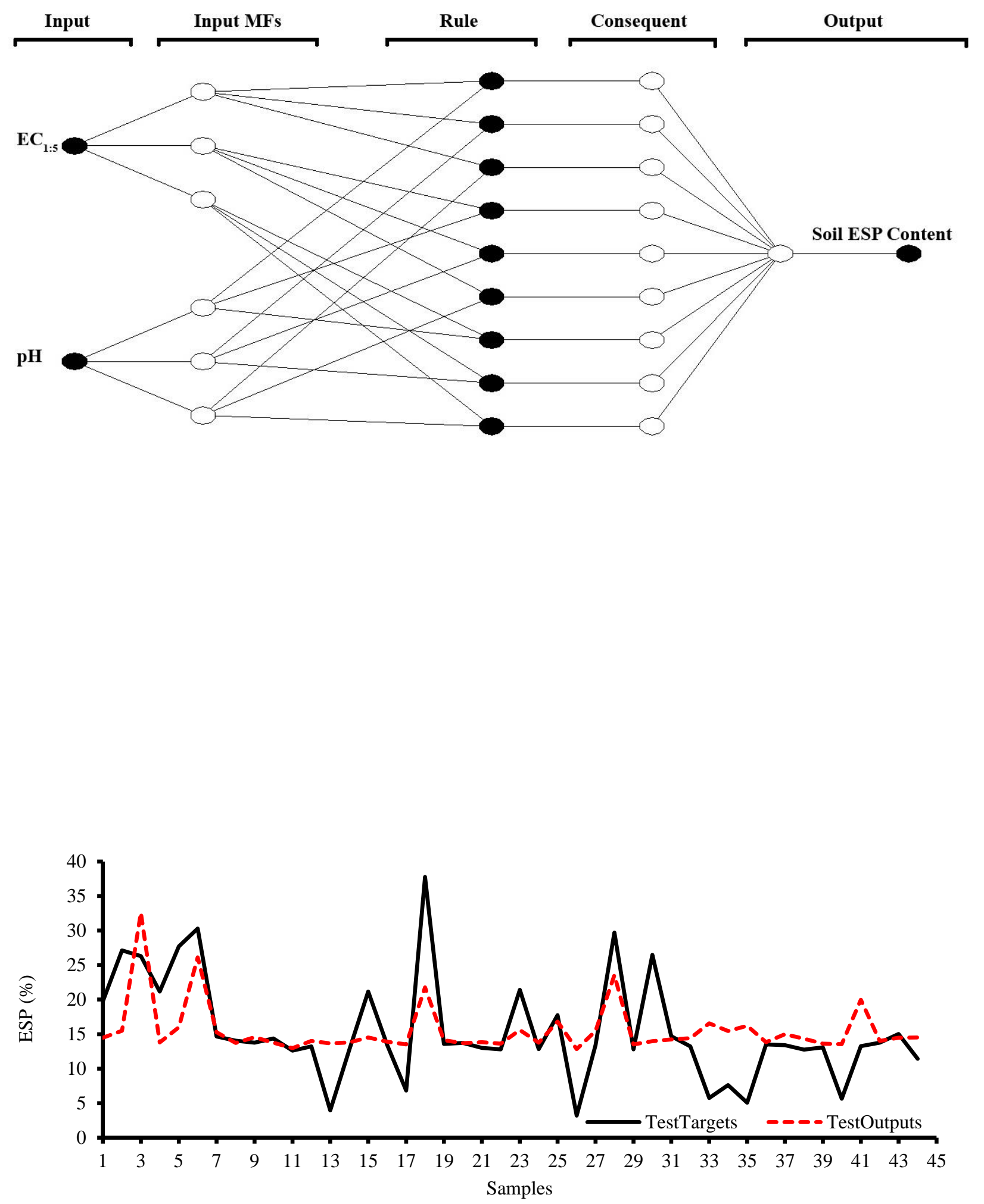


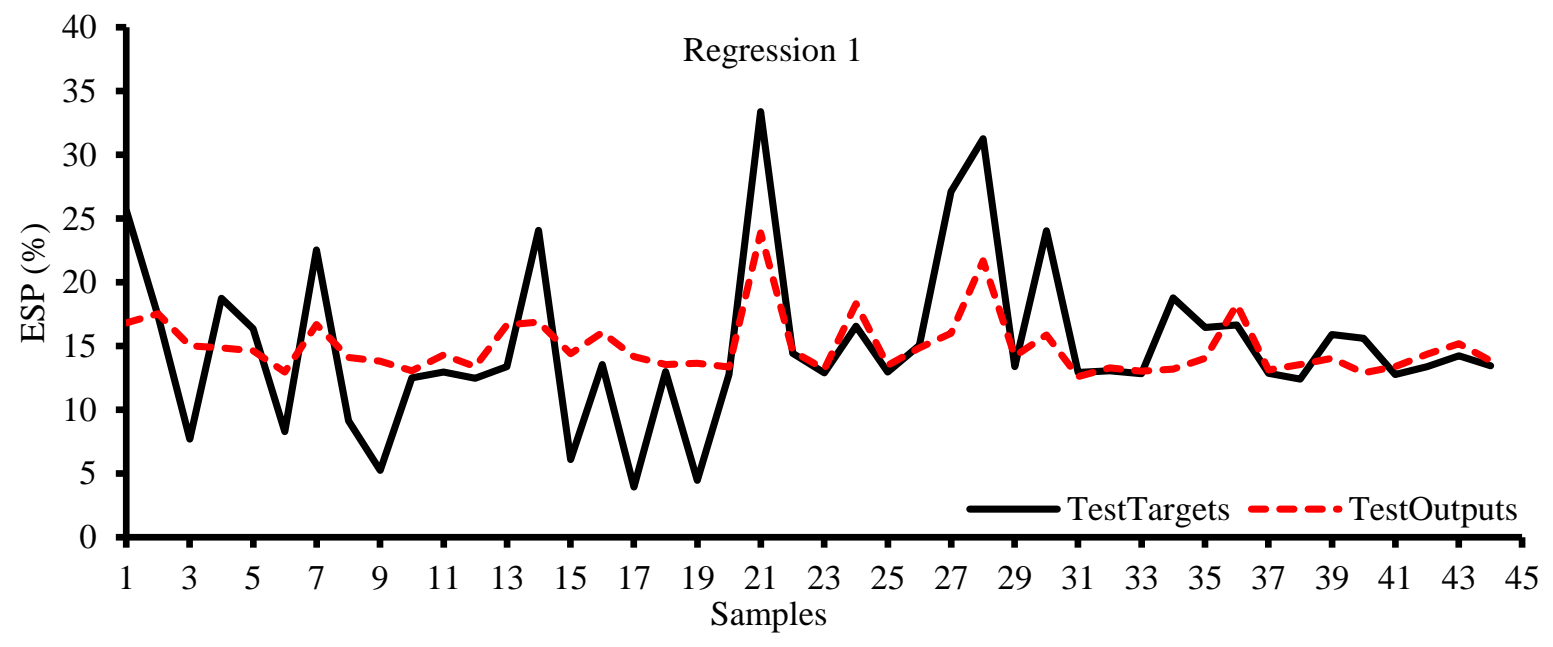



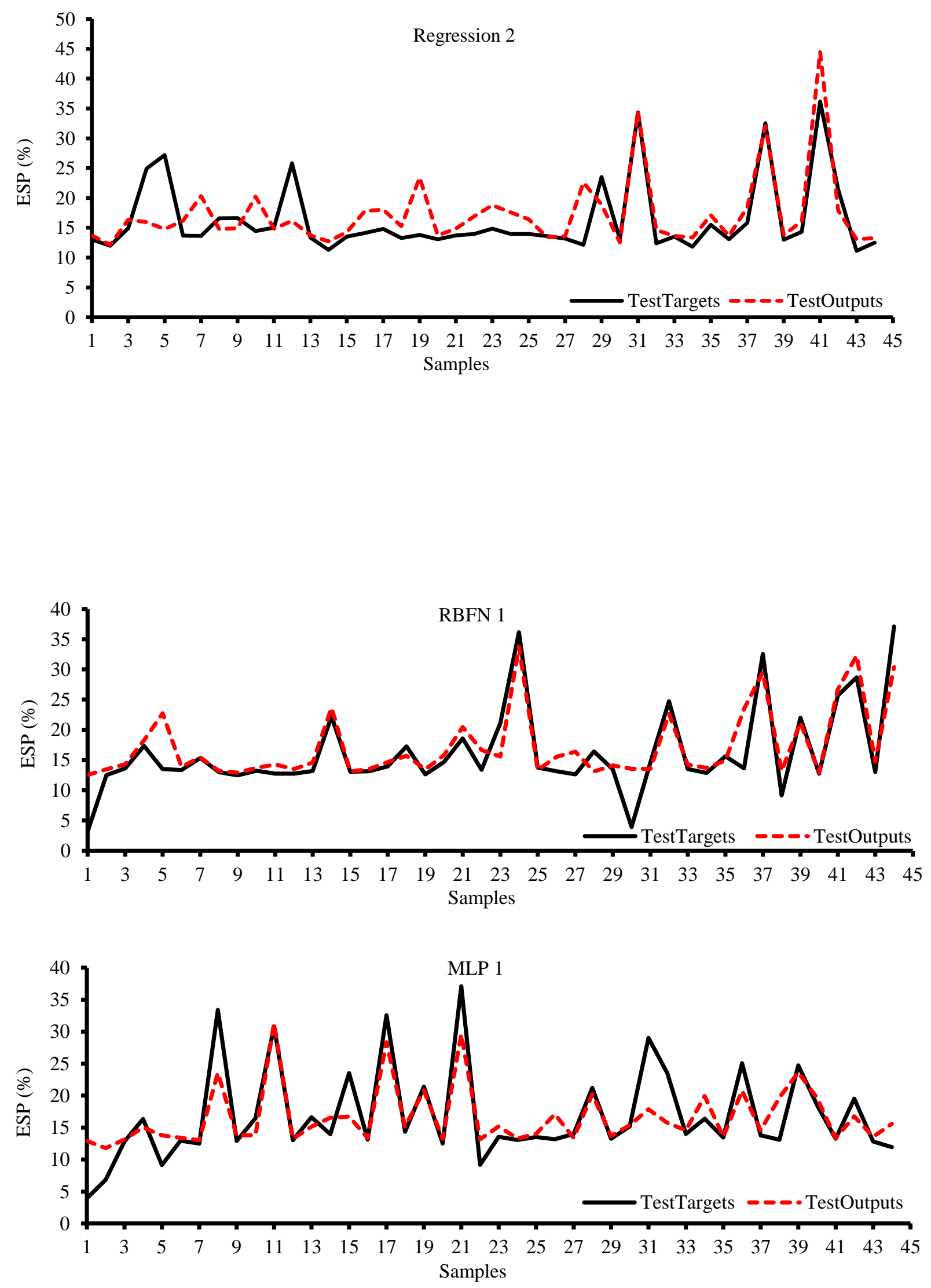

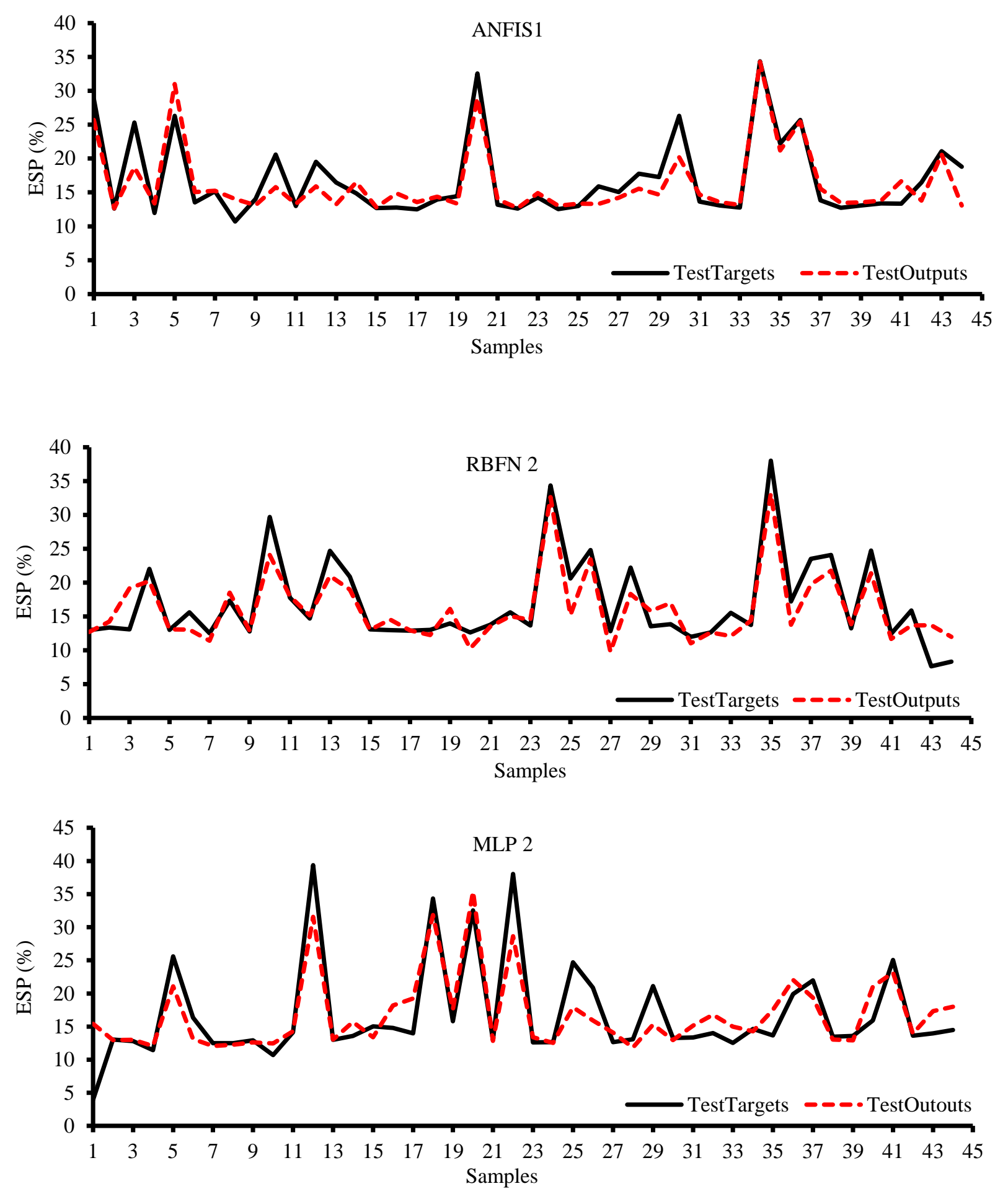

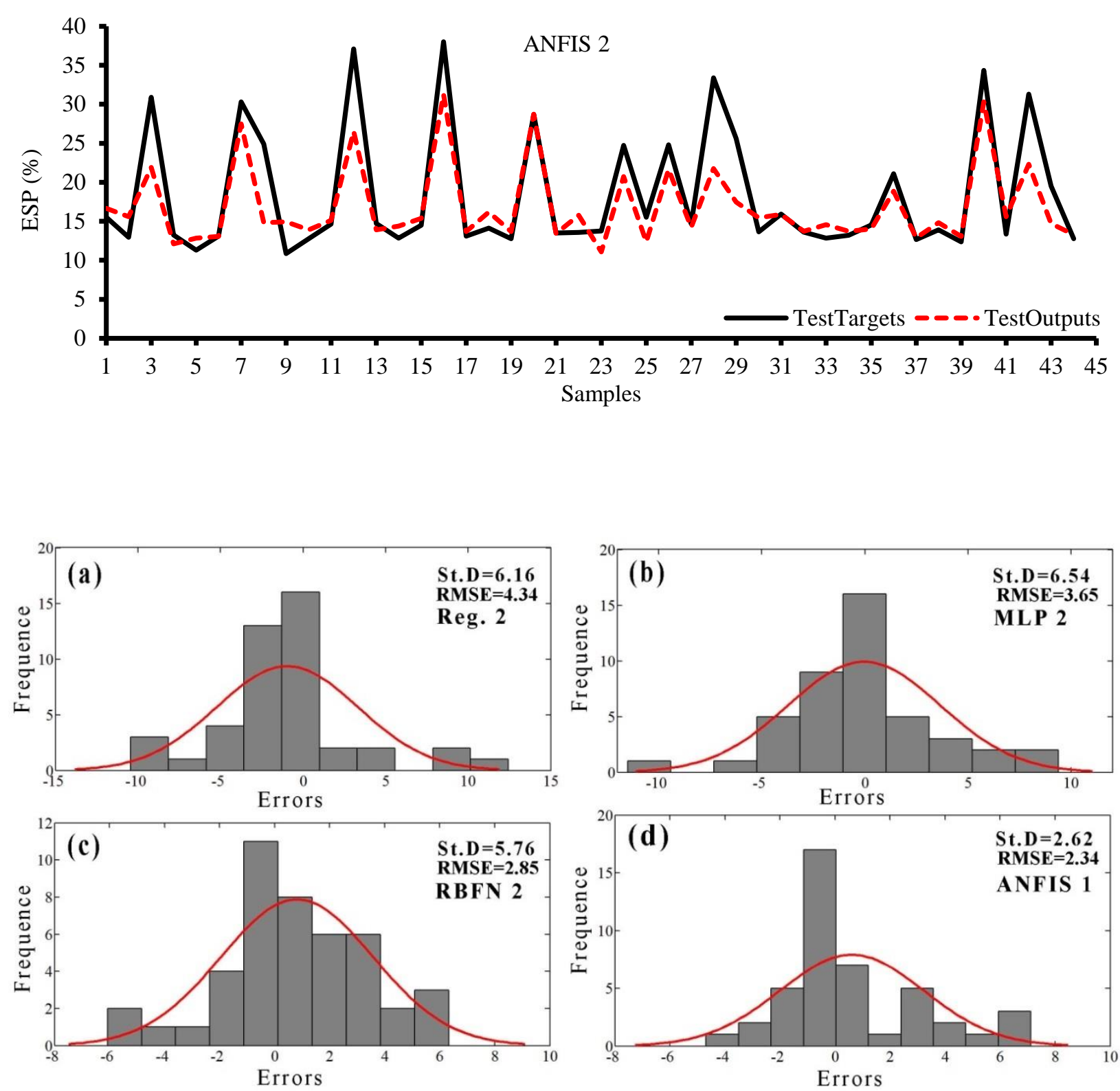


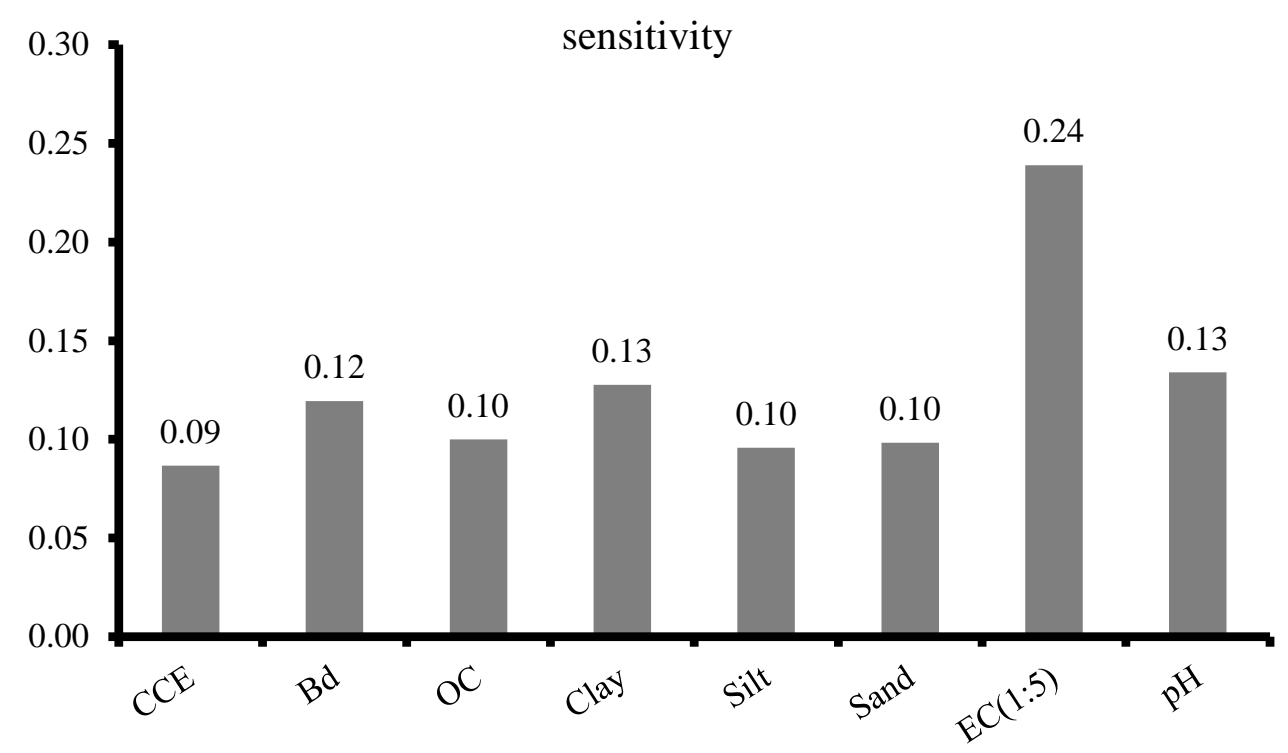

Table1

Statistical parameters of soil physical and chemical properties

\section{Table2}

Correlations between organic carbon (OC) and some soil properties 


\section{Table3}

ESP modeling results by modified equation of Robbins and Meyer (1990) in alluvial soils of Sistan plain

\section{Table4}

The Root Mean Squer Erorr (RMSE) of the independent variable, Coefficient of Determination

$\left(\mathrm{R}^{2}\right)$ and Model Efficiency Factor (MEF) of the soil ESP pedotransfer function

\section{Table 5}

Properties of resulted MLP, RBFN and ANFIS models

\section{Table 6}

Neuron weights used for sensitivity analysis

Fig. 1. Map showing the geographical setting of the study area, Sistan plain, Iran

Fig. 1. Schematic representation of the best ANN architecture

Fig. 2. ANFIS architecture of two input and nine rules

Fig. 4. Measured vs. predicted values of ESP using equation of Robbins and Meyer (1990) 
Fig. 5. Measured vs. estimated values of ESP using easily obtained soil properties in regression model 1

Fig. 6. Measured vs. estimated values of ESP using easily obtained soil properties in regression model 2

Fig. 7. Measured vs. estimated values of ESP using easily obtained soil properties in model 1 by RBFN, MLP and ANFIS

Fig. 8. Measured vs. estimated values of ESP using easily obtained soil properties in model 2 by RBFN, MLP and ANFIS

Fig. 9. Histogram curves of the best models: (a) Regression 2, (b) MLP 2, (c) RBFN 2 and (d) ANFIS 1 (St.D: standard deviation)

Fig. 10. Sensitivity coefficients histogram for some soil properties 